\title{
Programas de erradicação, reassentamento e urbanização das favelas: Delhi e Mumbai
}

\author{
VÉRONIQUE DUPONT \\ - MARIE-CAROLINE SAGLIO-YATZIMIRSKY
}

$\mathrm{E}$

STE ARTIGO comparativo focaliza as políticas públicas adotadas para as favelas das duas maiores metrópoles indianas, Delhi, a capital política, e Mumbai, o principal centro econômico. Depois de ter apresentado os contextos tanto demográficos quanto urbanísticos, ressaltaremos as tendências similares ou, ao contrário, tentaremos entender as divergências existentes nas políticas das favelas aplicadas no período pós-independência, isto é, depois de 1947. Como será mostrado, a explicação das principais diferenças tem como base as interações distintas de atores arraigados em contextos urbanos específicos. Os estudos de casos de Delhi e Mumbai conduzirão finalmente a uma reflexão mais geral sobre o "tratamento" das favelas na Índia.

Sendo o termo slum (favela) bastante utilizado na Índia, alguns esclarecimentos iniciais se fazem necessários. A lei de 1956 sobre as Áreas Faveladas (Desenvolvimento e Erradicação) - lei pioneira e de referência - considera favelas os setores antigos de habitação superlotados e degradados em que os edifícios "são, sob todos os aspectos, inadequados em termos de habitação humana". Essa definição pode aplicar-se a casas não habitadas por locatários ou proprietários com direitos legais, tal como no caso do antigo núcleo urbano de Delhi, que foi declarado "área favelada".

Uma segunda categoria de slums inclui estruturas autofabricadas, abrigos frágeis e barracos apinhados e insalubres chamados jhuggi-jhompris, em Delhi, e jhopad patties, em Mumbai. A natureza ilegal da ocupação da terra é um elemento comum nessa segunda categoria de habitação: para os urbanistas e o Poder Judiciário, isso significa terras ocupadas invadidas por posseiros, ou seja, terras ocupadas sem a autorização do órgão fundiário. Assim, a precariedade física da habitação e a precariedade do estado de ocupação estão associadas. São essas ocupações, ou favelas stricto sensu neste trabalho, que serão focalizadas na nossa análise.

Contexto demográfico e de assentamento

Aumento da população e expansão espacial

Tanto Delhi quanto Mumbai (ex-Bombay) enfrentaram influxos maciços 
de refugiados do Paquistão em decorrência da independência e da separação de 1947. Sua população aumentou assim drasticamente entre 1941 e 1951: de 700 mil para 1,4 millhão em Delhi, e de 1,4 milhão para 2,3 milhões em Mumbai.

Delhi continuou crescendo numa proporção considerável em razão da contribuição dos migrantes por motivos econômicos; em 2001 (último censo), a aglomeração urbana deu conta de 12,8 milhões de habitantes. A localização geográfica de Delhi, na planície do Gange, e a ausência de qualquer barreira física significante que impeça o progresso da urbanização favoreceram a expansão urbana multidirecional e levaram às densidades médias de 163 habitantes por hectare em 2001 (dentro dos limites oficiais da aglomeração). A extensão urbana ultrapassou os limites do Território da Capital Nacional de Delhi em direção aos Estados vizinhos e foi incluindo as cidades periféricas, levando ao desenvolvimento de uma megacidade de aproximadamente 21 milhões de habitantes hoje.

$\mathrm{O}$ crescimento rápido de Mumbai durante todo o século XX se deve às suas indústrias manufatureiras que atraem a mão de obra migrante da Índia. Em 2001, a população da municipalidade alcançou 11,9 milhões, e toda a Aglomeração Urbana da Grande Mumbai, 17,7 milhões, isto é, aproximadamente 19 milhões de habitantes hoje. O efeito do fluxo migratório foi diminuindo a partir dos anos 1980, na medida em que a cidade foi se transformando de metrópole industrial para um centro financeiro e de serviços. A expansão espacial de Mumbai foi refreada por restrições geomorfológicas e ecológicas. Essa ilha-cidade não tem possibilidade de expandir-se, a não ser em direção ao lado norte, e está fortemente congestionada, com uma densidade média de 272 habitantes por hectare, e até $1.200 \mathrm{em}$ determinadas favelas. Sua faixa costeira, ocupada por mangues, é classificada como zona de não desenvolvimento (NDZ), e sua vasta floresta urbana é um Parque Nacional protegido.

\section{Impacto da globalização sobve a reestruturação urbana}

Desde os anos 1990, que marcam na Índia o início da liberalização e abertura econômica ao mercado internacional, Delhi e Mumbai experimentaram uma reestruturação do seu espaço urbano alinhada com as exigências das cidades globalizadas. As transformações foram inicialmente mais conspícuas em Mumbai, portal para as empresas de nível internacional. A pressão sobre os favelados foi se intensificando quando a cidade começou sua reconversão de centro industrial para "cidade global", marcada pela presença de empresas e de novos center business districts (CBD). Todo esse processo, exigindo infraestruturas, um sistema de transporte avançado e redes de comunicação, conforme proposto no Plano Regional para a Região Metropolitana de Bombay, reestruturou o espaço urbano, reforçando a exclusão socioespacial dos pobres. Sendo capital do país e, portanto, sua vitrina, aspirando, além disso, tornar-se uma metrópole global, Delhi está também sofrendo transformações consideráveis em suas infraestruturas, as quais resultaram em erradicações de favelas em grande escala. Os preparativos em curso para os Jogos do Commonwealth 2010 em Delhi reforçam essa tendência. 


\section{Favelas e invasões: contexto e extensão do "problema"}

Com as fortes restrições demográficas da pós-independência e a tremenda pressão exercida sobre a terra, as políticas públicas de habitação e planejamento urbanos não conseguiram preencher a demanda. No final, foram as classes médias baixas, e as classes trabalhadoras as mais afetadas pela penúria de habitações - conforme observado nas outras cidades indianas.

Em 1957, contudo, Delhi foi dotada de uma autoridade especial responsável pela fiscalização do desenvolvimento planejado da capital mediante a elaboração e execução de um Plano Mestre: a Autoridade de Desenvolvimento de Delhi (DDA). Todas as terras localizadas dentro dos limites urbanizáveis de Delhi foram colocadas sob o controle da DDA, que assumiu também o cargo de uma agência imobiliária. Apesar dos seus objetivos sociais declarados, a DDA deixou de cumprir a obrigação de reservar uma porção significante de terra residencial para os grupos de renda mais baixa (Dupont \& Ramanathan, 2007).

Em Mumbai, além do fracasso das políticas de habitação, especialmente em relação aos grupos de baixa renda, duas outras razões contribuíram para o espantoso desenvolvimento das favelas: as restrições jurídicas que prejudicaram a construção das habitações convencionais regularizadas (Saglio-Yatzimirsky 2002) e a pressão do rápido desenvolvimento imobiliário desde os anos 2000, reduzindo a oferta de moradias populares.

Tanto em Delhi quanto em Mumbai, a invasão da terra desocupada e a favela parecem ser as únicas opções para os pobres da área urbana, já que não há nenhuma outra opção em relação a um preço aceitável no setor formal. Além das condições de moradia improvisada, congestão e falta de serviços urbanos básicos, os posseiros sem alternativas recorriam frequentemente à ocupação de lugares insalubres e/ou perigosos que provavelmente não atrairiam a atenção dos investidores e construtores num futuro imediato. Com o passar dos anos, a consolidação das estruturas, o acréscimo de um andar e o desenvolvimento de um setor de locação contribuíram para o aumento da densidade residencial.

Apesar da aplicação de políticas de moradia e de programas de erradicação de favelas, a população de posseiros em Delhi continuou crescendo dos anos 1950 aos 1990, não obstante a notável exceção do Estado de emergência de 1975-1977 (suspendendo democracia e liberdades civis) durante o qual aproximadamente 750 mil pessoas foram removidas à força das favelas e das terras invadidas na cidade, sendo enviadas para lugares periféricos. Em 1998, aproximadamente três milhões de pessoas viviam em 1.100 jhuggi-jhompris, respondendo por aproximadamente $27 \%$ da população da aglomeração de Delhi (índice comparado com 4,4\% em 1951), ${ }^{1}$ mas ocupando menos de $5 \%$ do solo da cidade (Kundu, 2004). Em razão da grande quantidade de expulsões na última década, a população de posseiros sem dúvida reduziu, contudo não se dispõe de nenhuma estimativa oficial confiável (Dupont, 2008).

Antes da recente e maciça tendência à demolição, as ocupações ilegais 
ocorriam em toda a capital, insinuando-se nos interstícios do tecido urbano (Mapa 1). Uma especificidade das ocupações em Delhi é a posse pública da terra que elas tomam, e mais de $80 \%$ dessa estariam sob jurisdição da DDA, uma situação decorrente do monopólio da aquisição de terras pela DDA desde os anos 1960.

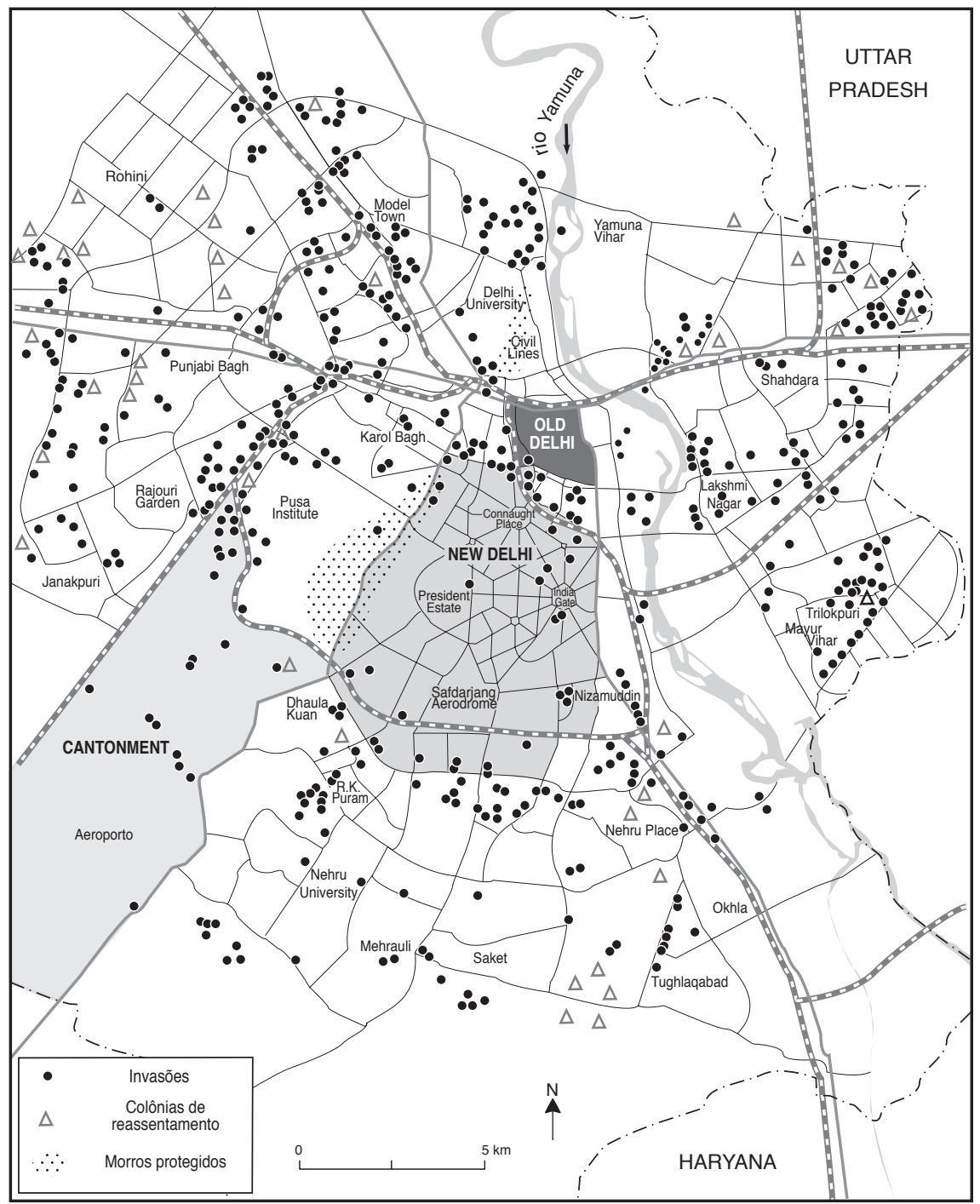

(C) V. Dupont - LCA, Bondy - IRD.

Fonte: Slum \& Jhuggi Jhompri Department, Municipal Corporation of Delhi, 1990; Sabir Ali, Slums within Slums: a study of resettlement colonies in Delhi, New Delhi: Council for Social Development, 1990.

Digitalização: UMR ESPACE, Montpellier.

Mapa 1 - Invasões e lugares de reassentamento na aglomeração de Delhi (1990).

Mumbai concentra a maior população favelada de todas as cidades indianas: 6,5 milhões de favelados na municipalidade da Grande Mumbai de acordo 
com o censo de 2001, representando $54 \%$ de sua população total. Essa proporção é consideravelmente mais elevada do que na municipalidade de Kolkata (32\%) e na municipalidade de Delhi (19\%). A porção de população favelada em Mumbai foi aumentando de modo contínuo, apesar das demolições violentas e em grande escala dos assentamentos não autorizados durante o período de emergência e durante as expulsões de 2004.

Embora as favelas abriguem metade da população da Grande Mumbai, elas ocupam apenas $8 \%$ do solo do centro da cidade (Das, 2003). A sua localização, de início nas zonas centrais, próximo das redes de transporte e dos locais de trabalho, vai mudando progressivamente para as periferias, em decorrência das políticas de remoção (Mapa 2). A maior favela em Mumbai, Dharavi, que abriga aproximadamente 800 mil residentes, está, contudo, localizada no centro da cidade (Saglio-Yatzimirsky, 2002). Ao contrário de Delhi, em Mumbai, praticamente metade da terra ocupada por posseiros pertence a proprietários particulares, sendo o resto de propriedade de órgãos públicos. Essa variedade, em termos de propriedade fundiária, implica complicações na aplicação das políticas de favelas em Mumbai.

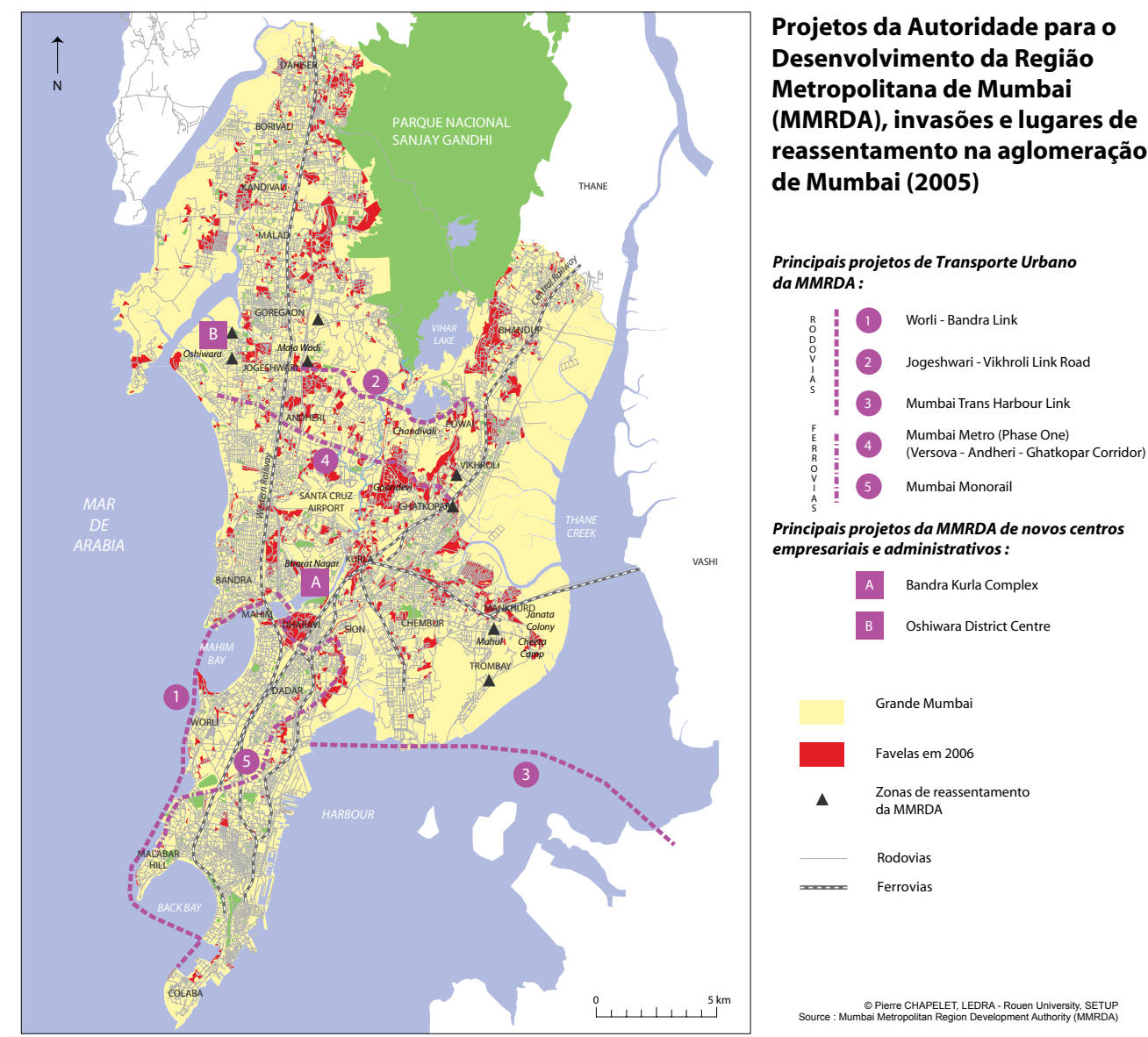

Mapa 2 - Invasões e lugares de reassentamento na aglomeração de Mumbai (2005). 


\section{Políticas públicas relativas às favelas}

Ao enfrentarem a extensão e persistência de favelas ilegais, os governos e autoridades municipais realizaram vários tipos de intervenções ad hoc: prestação de serviços básicos como parte de programas mais amplos de redução da pobreza, urbanização e reassentamento em lugares alternativos. As experiências de Delhi e Mumbai ilustram esses três tipos de abordagens. Esses vários programas podem ser patrocinados ou empreendidos pelo governo central, estadual ou pelas autoridades municipais; eles também podem ser financiados por organizações internacionais ou ser inspirados por elas.

Em Delhi, a autoridade responsável pelo desenvolvimento do solo e pelas políticas de habitação é a Autoridade de Desenvolvimento de Delhi (DDA), sob jurisdição do Ministério de Desenvolvimento Urbano da União. Um Departamento Jhuggi-Jhompri e de Favela (JJ), parte da municipalidade de Delhi (MCD), está encarregado da aplicação de programas para favelas e ocupações de posseiros.

Em Mumbai, as autoridades competentes para o planejamento urbano e a habitação na metrópole são a Autoridade para o Desenvolvimento da Região Metropolitana de Mumbai (MMRDA), sob a jurisdição do governo de Maharashtra, e a Autoridade para o Desenvolvimento da Área e Habitação de Maharashtra (MHADA). Em 1991, a Autoridade para a Urbanização das Favelas (SRA) foi criada como parte da MHADHA para atuar como autoridade de coordenação individual para a reurbanização de favelas.

\section{Antecedentes históricos e legislativos}

Logo depois da independência, a proliferação de favelas na capital foi considerada questão da maior importância. O Parlamento decretou a Lei das Áreas Faveladas (Melhoria e Erradicação) de 1956, uma lei pioneira que inclui medidas para a melhoria do antigo parque habitacional em determinados casos e a demolição de edifícios deteriorados em outros. A lei foi aplicada primeiro em Delhi e estendida a outras grandes cidades, incluindo Bombay, até a adoção da Lei das Áreas Faveladas de Maharashtra (Melhoria, Erradicação e Reurbanização) em 1971. No entanto, a Lei das Áreas Faveladas não foi concebida para encaminhar a questão dos assentamentos não autorizados. Assim, a tentativa de evitar a proliferação de ocupações levou à adoção de leis específicas e a decisões judiciárias que consideram essas ocupações invasões ilegais e um crime de jurisdição de um tribunal.

\section{Melhoria dos serviços básicos das favelas}

A melhoria das condições de vida nas favelas existentes, a saber, por meio do fornecimento de serviços básicos (sistema de fornecimento de água, latrinas, iluminação das ruas), já estava prevista no primeiro Plano Diretor para Delhi (1962-1981) e no Programa de Melhoria de Favelas lançado em 1971 em Mumbai. Inicialmente, essa proposta de melhoria foi concebida como medida temporária enquanto se aguardava que os posseiros fossem remanejados (Banerjee, 
1994). Os planejadores e governos sucessivos se deram forçosamente conta de que os objetivos iniciais das políticas públicas, isto é, habitação para todos a um preço aceitável, permaneceram um sonho distante por causa das restrições econômicas, e, além disso, que as favelas não eram um simples fenômeno transitório; em consequência, a melhoria das favelas foi admitida como opção alternativa em longo prazo (Banerjee, 2002). Em 1972, o governo central lançou assim o esquema de melhoria das favelas urbanas, destinado a fornecer uma infraestrutura básica em zonas oficialmente designadas como favelas. Outros esquemas com objetivos similares ou mais abrangentes seguiram, influenciados especialmente pelo Projeto de Serviços Básicos Urbanos para os desfavorecidos das áreas urbanas iniciado pela Unicef em âmbito mundial nos anos 1980.

Essa abordagem pragmática (embora de curto prazo) - melhorando as condições de vida dos posseiros onde eles estavam baseados - não lhes garantia, no entanto, os direitos de ocupação nem os protegia das demolições se - como em Delhi - o órgão fundiário apresentasse projetos de "maior" utilidade em terras ocupadas (Priya, 1993).

O fornecimento de serviços básicos para os desfavorecidos urbanos, focalizado nas favelas, faz novamente parte da agenda de um programa nacional patrocinado pelo governo central - a Missão de Renovação Urbana Nacional Jawaharlal Nehru -, que foi lançado em dezembro de 2005, sendo destinado a 63 cidades principais, incluindo Delhi e Mumbai.

\section{Procedimentos de reassentamento}

A abordagem favorecida pelo órgão administrativo de Delhi relativo às ocupações a partir do fim dos anos 1950 foi a erradicação com reassentamento em colônias. Isso não implica um programa habitacional, mas simplesmente o reassentamento em lotes desenvolvidos, em lugares teoricamente providos de infraestrutura básica. O critério de elegibilidade se referia a uma data-limite de chegada à ocupação. As famílias que chegassem após essa data não tinham mais direito ao benefício do reassentamento e eram assim desapropriadas do local de habitação sem nenhum tipo de indenização ou acordo alternativo. Esse esquema foi modificado em várias ocasiões, com a introdução de certas restrições como a abolição do arrendamento do solo no lugar em que um sistema de licença foi instituído (Ali, 1990). Além disso, o princípio de elegibilidade com base numa data-limite de chegada permanece um critério imperioso em todas as políticas de reassentamento - sendo a presente data: dezembro de 1998.

Entre os anos 1960 e 1970, 44 núcleos de reassentamento foram desenvolvidos para remanejar os habitantes das ocupações: em flagrante contradição às recomendações do primeiro Plano Diretor da cidade, praticamente todos esses núcleos eram localizados na periferia daquela época (Mapa 1).

De acordo com a política contínua das favelas em Delhi, adotada em 1990-1991, conjectura-se a remoção das invasões e sua transferência quando estão localizadas em terra requisitada para executar projetos de “interesse pú- 
blico maior" (GNCTD, 1999). O tamanho do lote repartido foi reduzido a 18 metros quadrados para as famílias de posseiros pré-1990, e a 12,5 metros quadrados para as famílias que possuíssem senhas de racionamentos emitidas de 1990 a 1998. Isso significa reconstruir assentamentos superlotados - um critério caracterizando uma área favelada. De acordo com o Departamento J. J. e de Favela, aproximadamente 65 mil famílias de posseiros foram removidas até 2008 segundo esse procedimento de assentamento, o que significa que um número consideravelmente mais elevado teve suas casas demolidas. Os núcleos de assentamento desenvolvidas nesses últimos 10 anos estão localizadas bem mais longe do que os lugares de reassentamento anteriores, de 30 a 40 quilômetros do centro da cidade (Mapa 3).

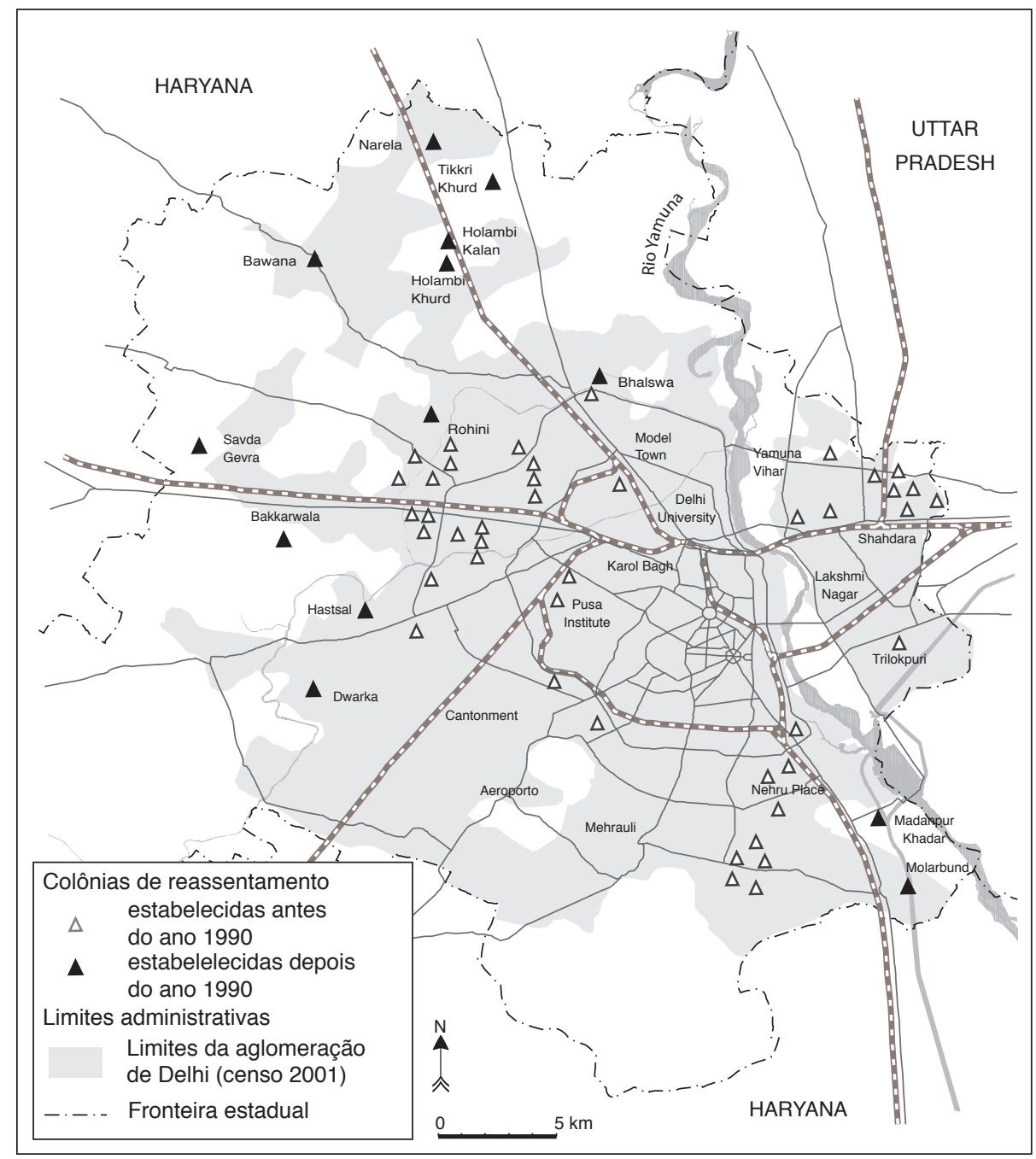

(C) V. Dupont (IRD), P. Chapelet (Setup).

Fonte: Slum and Jhuggi-Jhompri Department, Municipal Corporation of Delhi.

Mapa 3 - Lugares das colônias de reassentamento no território administrativo de Delhi (2007). 
Embora as demolições de favelas ocorressem em toda a área urbana, as maiores delas afetaram as zonas central e sul da aglomeração urbana e as vizinhanças do aeroporto, isto é, zonas caracterizadas por valores imobiliários altos. Em 2004-2006, elas afetaram enormemente as ribanceiras do Rio Yamuna relacionadas com a urbanização da parte da frente do rio e com a construção do Games Village para os Jogos do Commonwealth 2010, causando a expulsão de aproximadamente 300 mil pessoas (OMCT/HIC-HLRN, 2004). ${ }^{2}$

Em Mumbai, o Banco Mundial influenciou a política de erradicação desde os anos 1980 financiando programas de lotes urbanizados, destinando parcelas para arrendamento com infraestrutura básica para reassentar favelados que deviam então construir sua própria casa. Em 1986, a política do Banco Mundial recomendou o reassentamento dos habitantes registrados cuja favela seria demolida por causa das condições ambientais arriscadas ou, na maior parte do tempo, em razão dos projetos de urbanização (Risbud, 2003). Os favelados devem provar a sua chegada antes de uma data-limite ( $1^{\circ}$ de janeiro de 1995 , conforme a política atual) a fim de se registrar nos programas de reassentamento.

Dois projetos de infraestrutura de grande escala levaram à remoção maciça de favelas e a programas de reassentamento importantes: o Projeto de Transporte Urbano de Mumbai (MUTP, 2002) e o Projeto de Infraestrutura Urbana de Mumbai (Muip, 2006). Ambos os projetos estão sob a responsabilidade do MMRDA e são parcialmente financiados pelo Banco Mundial. Outros projetos acarretaram despejos consideráveis sem reassentamento entre novembro de 2004 e março de 2005; foram demolidas 90 mil casas, afetando aproximadamente 450 mil pessoas. Essas estimativas, efetuadas pelo Tribunal Popular Indiano dos Direitos Humanos e do Meio Ambiente, podem ser confrontadas com os números oficiais de menos de 50 mil casas.

\section{Esquemas de urbanização de favela}

A urbanização foi a abordagem recomendada na documentação da política nacional, tal como a Política de Habitação Nacional de 1992 ou o Projeto de Política Nacional de Favelas de 1999.

Em Mumbai, no fim dos anos 1980, no novo contexto de liberalização econômica, a urbanização e a concessão de títulos fundiários para os favelados se tornaram a abordagem preferida, com o envolvimento ativo dos construtores privados.

O primeiro projeto de urbanização de favelas foi introduzido em 1991 para favelas localizadas em terras de propriedade privadas; ele foi revisto e estendido, em 1995, para favelas localizadas em terras pertencendo a instituições do governo do Estado. O princípio foi encorajar promotores particulares a construir edifícios de múltiplos andares no mesmo lugar para as famílias faveladas, utilizando apenas parte da terra, e a utilizar o resto da terra assim desimpedido para o assentamento residencial ou comercial no mercado aberto. Os promotores puderam assim obter um lucro suficiente para cobrir o custo de construção das habitações para os pobres; eles se beneficiaram também de incentivos adicionais. 
O governo de Estado eleito em 1995, chefiado pelo Shiv Sena - um partido nacionalista hindu de direita -, militou a favor de uma Mumbai "limpa", livre da mancha da pobreza, e tinha a ambição de fornecer 800 mil habitações a quatro milhões de favelados. No entanto, o impacto do Projeto de Urbanização de Favelas permaneceu limitado: aproximadamente 60 mil unidades habitacionais foram construídas até 2006. Foi uma grande dificuldade encontrar terras públicas desocupadas para a transferência temporária das famílias faveladas. O esquema foi criticado pela corrupção que ele promove (Weinstein, 2008), bem como por abrir as portas ao desabrochar de uma máfia imobiliária e por criar "favelas verticais".

A urbanização está readquirindo alguma extensão com o Projeto ${ }^{3}$ de Urbanização de Dharavi que incitou o exagero da mídia. Uma inovação importante é que se espera que os promotores entreguem um distrito completo, incluindo edifícios residenciais, comodidades cívicas, centros comerciais e um complexo industrial. Em seguida, embora o projeto seja executado por meio do SRA, ele é totalmente financiado por promotores particulares. Hoje, o plano de habitação é destinado a aproximadamente 300 mil favelados elegíveis, registrados como residentes nos censos eleitorais de 1995; todos os outros terão que abandonar o lugar. $\mathrm{O}$ atual abrandamento econômico prejudicou de modo significativo o projeto, que sublinha a dependência de tal parceria no mercado imobiliário.

Em Delhi, a estratégia tripartida adotada em 1990-1991 pelo governo inclui "a melhoria mínima para os jhuggi-jhompris, cujas zonas de invasão não são requeridas pelos órgãos fundiários envolvidos por mais 15 a 20 anos para qualquer execução de projeto" (GNCTD, 1999). No entanto, essa opção foi empreendida apenas em pouquíssimos casos. Isso significa, de fato, uma versão mais completa do esquema de desenvolvimento do meio ambiente, sem nenhuma regularização de título de posse para os favelados, e não pode ser comparado aos projetos de urbanização básica executados em Mumbai. Apesar de tudo, novos projetos de urbanização básica inspirados no modelo de Mumbai, que acarretarão a construção de edifícios de vários andares por meio de parceria público-privada, estarão prontos logo, como o projeto piloto de Tehkhand na periferia do sul de Delhi.

\section{Recapitulando: principais similaridades e divergências}

Tanto em Delhi quanto em Mumbai, a remoção das invasões é, em princípio, sujeita ao requerimento da terra para projetos de utilidade pública; contudo, a interpretação do que constitui o "interesse público" está aberta para a variedade de interpretações, especialmente mediante a intervenção dos tribunais. Desde o início dos anos 2000 e a nova tendência a favor do reassentamento das favelas em Mumbai - apesar do Projeto de Urbanização específico de Dharavi -, a dinâmica global comum em ambas as cidades é expulsar os favelados das zonas centrais e reassentá-los em zonas periféricas remotas ou, algumas vezes, em zonas não destinadas à urbanização. 
Além disso, em ambas as cidades, o princípio de elegibilidade baseado numa data-limite restringiu o impacto dos programas de urbanização e reassentamento na erradicação das favelas; essa política não trouxe uma resposta sustentável para a necessidade habitacional dos pobres da área urbana. As famílias excluídas dos programas recorreram à ocupação de outros lugares ou ao arrendamento de habitações em favelas já congestionadas. Em caso de reassentamento, as longas distâncias entre os novos lugares e os anteriores afetam negativamente o acesso ao emprego e provavelmente acarretam, como em Delhi, as práticas de revenda.

Embora as demolições em massa tenham afetado os favelado em ambas as metrópoles, nesses 50 últimos anos, o impacto da remoção de favelas foi maior na capital, em razão do tamanho da população de suas favelas. Além disso, as políticas das favelas aplicadas em Delhi foram menos abrangentes e generosas do que em Mumbai. Em primeiro lugar, as melhorias ambientais ou a urbanização básica das favelas em Delhi nunca incluíram a concessão de títulos fundiários aos ocupantes nos locais existentes, e, até hoje, nenhum programa apropriado de urbanização básica de favelas foi levado a cabo. A única forma de título em Delhi foi concedida em locais de reassentamento e, desde 1993, exclusivamente numa base de licença. Enquanto em Mumbai as opções válidas foram os programas de reassentamento ou urbanização mínima, em Delhi, os esquemas de reassentamento consistem em simples remoções nos lugares aptos para a construção. Por último, a contribuição financeira das famílias faveladas elegíveis para os projetos de urbanização ou reassentamento é bem mais elevada em Delhi.

Essas grandes divergências, bem como os aspectos específicos da execução dos programas, derivam de contextos urbanos diferentes e várias interações dos atores nas duas cidades, e serão agora examinadas.

\section{Várias interações de atores em diferentes contextos}

Já sublinhamos algumas especificidades em Delhi e Mumbai. Delhi é a sede tanto do governo central, do governo estadual e da Suprema Corte da Índia; o seu regime urbano é dominado pelo poder da administração pública via o DDA e (pela última década) dos tribunais de justiça que emergiram como atores decisivos no palco da governança urbana. Como capital nacional, é a peça mestre do país, o que se espera refletido em sua paisagem urbana. Em Mumbai, os atores urbanos são essencialmente impulsionados pelos interesses econômicos em jogo na cidade hoje. Consequentemente, as políticas referentes às favelas nas duas metrópoles são impelidas por diversas forças, atores e lógicas. Em Mumbai, as operadoras principais envolvidas nas políticas de favelas e em sua execução apresentam mais diversidade do que em Delhi e incluem três atores cujo papel não é tão significante (ou ainda não?) em Delhi: o Banco Mundial, os construtores e promotores privados, e as ONG. Aqui convém relembrar a importante tradição do ativismo social específico de Maharashtra. 


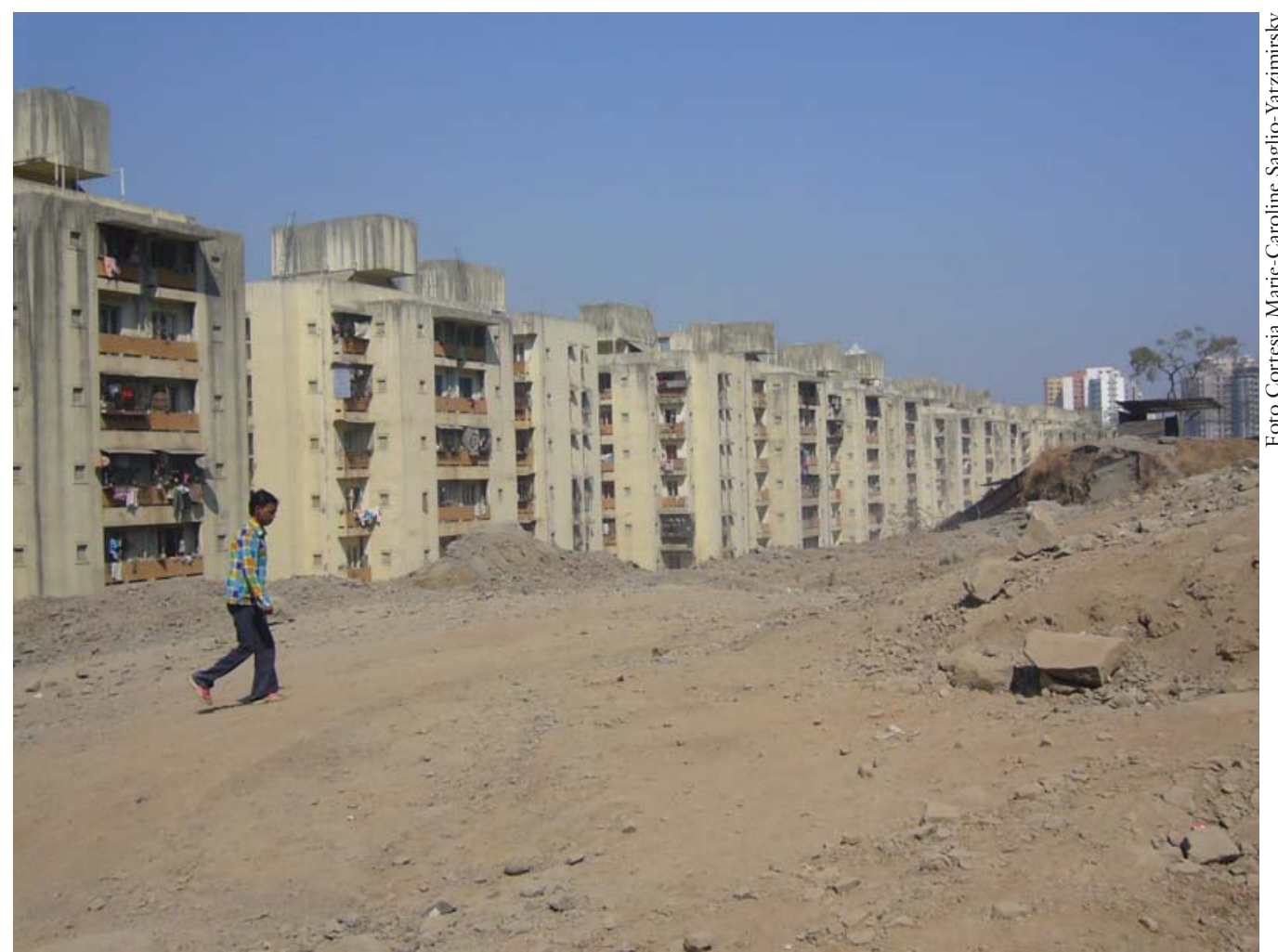

Imóveis de reassentamento do projeto Sangarsh Nagar, em Chandivali, Mumbai, na India.

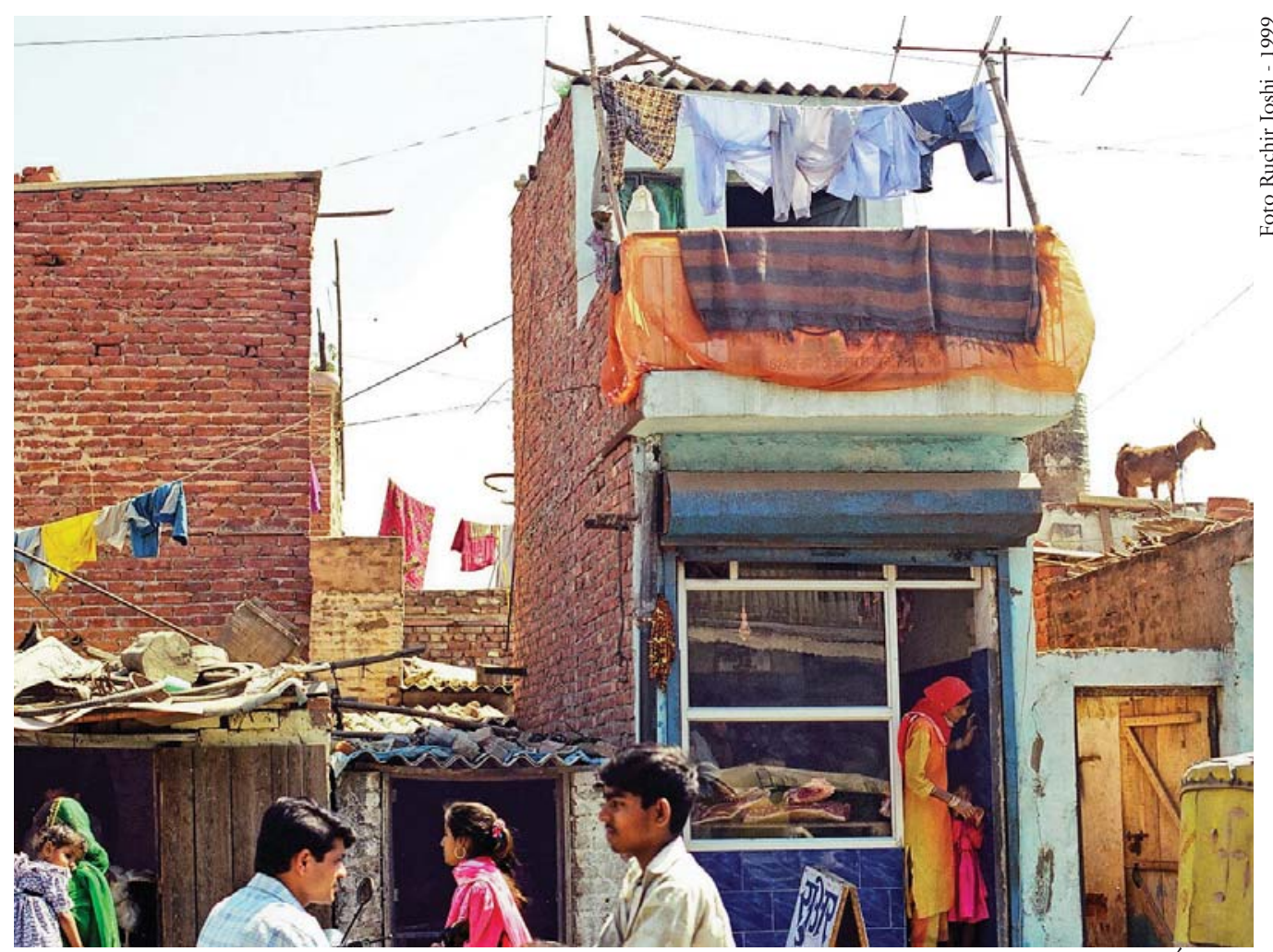

Construção de lajes sem segurança em favela situada em um bairro ao sul de Delhi, na Índia. 


\section{Lógica administrativa versus lógica econômica?}

A situação de Delhi como capital nacional explica a perspectiva da esfera de ação direta do governo central no desenvolvimento urbano do seu território, por meio do DDA, mesmo depois de o Território da Capital Nacional ter adquirido o status de um quase Estado em 1991, visto que o governo central deteve o controle sobre a terra. A designação do DDA como agência imobiliária para Delhi em 1967, mesmo para a habitação social, consolidou o controle dessa organização pública sobre o assunto favela. O monopólio do DDA sobre a aquisição e desenvolvimento de terras em Delhi explica, além disso, que programas em larga escala de reassentamento eram possíveis e representavam a estratégia prevalecente adotada para erradicar as favelas. Por último, em razão da posse pública exclusiva da terra ocupada pelas invasões em Delhi, o papel do DDA e da municipalidade no tratamento das favelas é reforçado: essas administrações são agentes na qualidade de órgãos fundiários, e como fazedores e executores de políticas.

Conforme explicado antes, as políticas de favelas em Mumbai, contrariamente a Delhi, promoveram a urbanização ou o reassentamento com a habitação. Isso é uma questão de escolha política, mas também a consequência da influência do Banco Mundial, que financiou vários projetos de urbanização e reassentamento em Mumbai desde o início dos anos 1980. Ele sempre recomendou a urbanização básica, e, quando o reassentamento era inevitável, assegurarse de que fosse realizado adequadamente.

Em Mumbai, a evolução das políticas referentes às favelas foi marcada pela retirada parcial do Estado quanto ao seu papel de fornecedor de serviços e alojamento até os anos 1980, passando para o de facilitador em programas de urbanização e reassentamentos a partir dos anos 1990 (Sanyal \& Mukhija, 2001), junto com a indução progressiva de promotores e construtores privados. A parceria público-privada se tornou o novo credo para financiar os programas de alojamento. Num contexto de escassez de terras e de alta pressão no mercado imobiliário, os promotores e construtores privados se tornaram atores predominantes nos programas relacionados com favelas - e, de modo mais geral, no desenvolvimento da terra urbana. Eles dão frequentemente contribuições aos partidos políticos pelas suas campanhas eleitorais e são subsequentemente retribuídos pelos políticos por meio da aquisição de terras. No entanto, a terra adquirida é frequentemente inadequada para a construção; por exemplo, terras da faixa costeira, às vezes, disponibilizadas de zonas de não desenvolvimento. Consequentemente, as políticas de Mumbai para as favelas são provavelmente distorcidas, visto que os interesses econômicos específicos das operadoras adquirem prioridade sobre os interesses dos favelados, abrindo a possibilidade de brechas para a corrupção (Weinstein, 2008). Ainda em Delhi, mesmo sem uma indução oficial por parte do setor privado nos projetos das favelas, a corrupção está amplamente difundida conforme demonstrado pelo caso da fraude que envolveu um especulador lidando com lotes alocados pelo DDA para os núcleos de reassentamento (o conto do escândalo "Chholegate" de 2007). 
Em Delhi, no entanto, a parceria público-privada se tornou também parte da estratégia de desenvolvimento urbano, sendo promovida por ambos, o DDA e o governo de Delhi. Eles lançaram consequentemente projetos pioneiros de urbanização e construção e unidades habitacionais por meio da parceria públicoprivada.

\section{O papel flutuante dos tribunais}

Até os anos 1990, os tribunais na Índia introduziram frequentemente despachos de suspensão que evitaram despejos de favelados (Ahuja, 1997) ou julgamentos, mostrando alguma compreensão pelas condições de vida dos pobres e as responsabilidades das autoridades municipais, e que notificaram estas últimas a fornecer serviços cívicos para os favelados (Ghertner, 2008). Em 1985, o caso "Olga Tellis versus municipalidade de Bombay" marcou uma etapa importante. Esse caso do Processo de Interesse Público (PIL) foi trazido para o tribunal na defesa dos direitos dos habitantes de rua para garantir um lugar para viver. $\mathrm{O}$ julgamento da Suprema Corte reconheceu o direito básico dos habitantes das favelas e de rua ao abrigo e declarou, além disso, que as casas dos posseiros não podiam ser demolidas durante as chuvas e sem um aviso prévio adequado (Ramanathan, 2006).

O discurso dos tribunais, no entanto, endureceu. Desde o início dos anos 2000, especialmente em Delhi, os julgamentos recentes dos tribunais contribuíram para reforçar a percepção dos favelados como invasores, autores de grilagem, sem admiti-los como vítimas do fracasso da política habitacional (Ghertner, 2008). Apesar de a política das favelas de Delhi ter manifestado alguma preocupação em proteger os interesses dos favelados - ou pelo menos introduziu algumas condições para a expulsão deles -, a intervenção do Judiciário nos últimos 15 anos minou consideravelmente a política (Ramanathan, 2006; Dupont \& Ramanathan, 2007).

Em muitos casos, a intervenção dos tribunais foi uma resposta a requerentes representando os interesses de associações residentes de bem-estar social ou industriais, ou, de modo mais geral, de grupos de rendimento médio e superior, que expõem considerações ambientais e de saneamento por meio de PIL e pediram a remoção de favelas da vizinhança, exacerbando assim o antagonismo entre os projetos sociais e ambientais. Por exemplo, o argumento da poluição do rio foi utilizado pelo Tribunal Superior de Delhi para justificar a remoção de todas as favelas localizadas ao longo do Rio Yamuna (2003). Em Mumbai, o requerimento preenchido pelo Grupo de Ação Ambiental em 1995 contra os grileiros no Parque Nacional Sanjay Gandhi levou à demolição de aproximadamente 50 mil estruturas não autorizadas (Zérah, 2007). Apesar disso, a intervenção do Judiciário a favor da erradicação das favelas provou ser mais decisiva em Delhi do que em Mumbai.

\section{$A$ ascensão da sociedade civil}

Em Mumbai, a retirada parcial do Estado está se dando não apenas por 
meio da parceria público-privada, mas também por um segundo tipo de parceria, iniciada pelo governo com as ONG que formalizou um esquema de reassentamento e urbanização nos anos 2000. As ONG que entraram inicialmente em ação para compensar a inação pública e para lutar contra a injustiça e demolição ao ajudar os favelados a se organizar e a se beneficiar melhor dos programas viram crescer seu envolvimento como promotor nos programas de reassentamento e urbanização. Isso resultou em confundir os papéis dos vários atores envolvidos em políticas de favelas e no risco de introduzir novos direitos adquiridos.

A ONG, que desempenha tradicionalmente uma parte principal no controle, intensifica frequentemente os papéis assumidos pelos órgãos governamentais de planejar ou executar, sem ter as forças inerentes necessárias (Dewan Verma, 2002). O papel crescente das ONG nos projetos de urbanização e reassentamento em Mumbai, conforme forem necessários para os órgãos de desenvolvimento a fim de lidar com os favelados, está abalando um tanto paradoxalmente a confiança da comunidade local. As ONG são hierarquicamente organizadas e chefiadas por ativistas profissionais que definiram claramente suas zonas de ação, as quais trazem obviamente conflitos e luta pelo monopólio de execução. ${ }^{4}$

Além disso, as associações dos favelados tendem a consolidar sua organização (Desai, 1995). Elas desempenham um novo papel e às vezes se opõem a determinadas políticas públicas, como no caso do Plano de Urbanização de Dharavi, em relação ao qual muitas associações residentes se levantaram como oponentes, desafiando-o.

O ponto interessante é notar a consciência crescente dos favelados afetados pelas políticas das favelas em relação às questões em jogo. Essa consciência é indubitavelmente parte da politização da questão (Dewan Verma, 2002). Também é a consequência da capacitação dos pobres por parte das ONG e dos ativistas com personalidades carismáticas que são, em parte, da intelligentsia de Mumbai. Comparado a Delhi, o papel das ONG e das organizações baseadas na comunidade, no que se refere à coordenação da resistência dos favelados e ao ajuste das condições de sua urbanização ou reassentamento, é muito mais efetivo; os ativistas a favor dos pobres são mais visíveis e mais eficientes nas campanhas de consciência; como resultado, os favelados em Mumbai parecem ser mais organizados e mais bem armados para negociar com outros investidores, tanto públicos quanto privados.

Em Delhi, a política Bhagidari - ou parceria com investidores - é o leitmotiv e paradigma dominante do governo desde 2000. No campo da política de favelas, houve uma tentativa de cooptação de ONG pelo governo, uma estratégia para controlar os grupos de oposição e fazer que as ONG realizem o trabalho como parte da política de governo, com o efeito esperado de silenciá-las. No entanto, isso não alterou a política geral; a execução dos projetos de reassentamento continuou sendo realizada pelas autoridades públicas envolvidas, e as ONG não estiveram envolvidos como promotores. De fato, as ONG e os movimentos 
de direitos humanos em Delhi, a despeito de seus protestos denunciando as demolições de favelas em grande escala e, em alguns casos, a brutalidade das expulsões (especialmente nas ribanceiras do Yamuna), não influenciaram a execução da remoção de favelas. Essa ausência de impacto pode ser explicada pelas intervenções dos tribunais, cujo poder domina o palco urbano na capital.

\section{Conclusão}

A população das terras ocupadas pelos posseiros em Delhi foi contida numa proporção muito menor do que em Mumbai. A capital do país demonstra, de certo modo, uma tolerância menor em relação às favelas. Em Mumbai, até os anos 1980, o Estado atuou principalmente como fornecedor de habitações por meio da urbanização básica, no que se refere às favelas notificadas. Em Delhi, o reassentamento sem habitação prevaleceu. Desde os anos 1990, as autoridades de Mumbai mudaram seu papel e tornarem-se facilitadores, habilitando outros parceiros privados (construtores e promotores) e ONG a desempenhar um papel maior na execução de programas relacionados com favelas.

Os atores privados em Mumbai desempenham uma parte que eles não possuem em Delhi, onde o setor público é muito mais significativo (como proprietário de terra e tomador de decisão). Além disso, Delhi é a sede do governo da União e da Suprema Corte, enquanto em Mumbai, a intervenção de órgãos internacionais (especialmente o Banco Mundial) também é importante para explicar a elaboração de políticas. De um modo geral, parece que o processo de tomada de decisão em Mumbai é compartilhado - ou pelo menos influenciado - por atores em número mais variado do que em Delhi; essa configuração, contudo, facilita a interferência de interesses privados, bem como a da corrupção.

Tanto em Delhi quanto em Mumbai, como em outras cidades indianas, as favelas oscilaram entre a ilegalidade e rejeição, de um lado, e a tolerância e o reconhecimento, do outro. As mudanças frequentes de governo em âmbito estadual resultaram numa ausência de continuidade ou consistência nas políticas que foram aplicadas, e, no caso da capital do país, a divergência política eventual entre o governo do Estado e o central agravou a situação. A interferência dos tribunais, que pode contradizer o princípio básico das políticas nacionais habitacionais e de favelas, tornou-se um obstáculo para a adoção de um "tratamento" consistente das favelas.

O Projeto da Política Nacional de Favelas, que foi elaborado e que circulou em 1999, não é ainda oficialmente adotado e menos ainda executado. Isso é um sintoma da inabilidade do governo da União em unificar e estabilizar uma posição clara para o tratamento das favelas. Pode também revelar a ascendência integrada das forças do judiciário e do mercado, e o enfraquecimento ou a retirada correlativa do Estado nesse assunto.

Notas

I Departamento Jhuggi-Jhompri e Favela, Municipalidade de Delhi. 
2 Essa estimativa é dada pela ONG Hazard Centre; embora seja difícil de avaliar as cifras reais, ela indica, contudo, a extensão das demolições que ocorreram dentro de um período de alguns meses.

3 Cf. <http://www.sra.gov.in>.

4 Ver Bautès \& Saglio-Yatzimirsky (2008) e o exemplo detalhado de ONG Sparc em $<$ http://www.sparcindia.org $>$.

Referências bibliográficas

AHUJA, S. People, law and justice. Casebook on public interest litigation. New Delhi: Orient Longman, 1997.

ALI, S. Slums within slums. A study of resettlement colonies in Delhi. New Delhi: HarAnand \& Vikas, 1990.

BANERJEE, B. Policies, procedures and techniques for regularizing irregular settlements in Indian cities. The case of Delhi. Amsterdam: Casa, Urban Research Working Papers 34, Universiteit Amsterdam, 1994.

Security of tenure in Indian cities. In: DURAND-LASSERVE, A.; ROYSTON, L. (Ed.) Holding their grounds. Secure land tenure for the urban poor in developing countries. London: Earthscan, 2002. p.37-58.

BAUTÈS, N.; SAGLIO-YATZIMIRSKY, M. C. Rehabilitation schemes in Mumbai: the impact of strategies and conflicts among the actors involved. In: Workshop Territorial exclusion and integration: impact of urban policies and law. Delhi, 31 Jan.-1 $\mathrm{O}$ Feb. 2008. Disponível em: <http://setup.csh-delhi.com>.

BOMBAY METROPOLITAN Region Development Authority. Draft Regional Plan for Bombay Metropolitan Region 1996-2011. 1995

DAS, P. K. Slums: the continuing struggle for housing. In: PATEL, S.; MASSELOS, J. Bombay and Mumbai, the city in transition. Delhi: Oxford University Press, 2003. p.207-34.

DDA. Work studies relating to the preparation of the Master Plan for Delhi. Delhi: Delhi Development Authority, 1957. v.1.

. Master Plan for Delhi 2021. Delhi: Delhi Development Authority, 2007. Disponível em: <http://www.dda.org.in/planning/master_plans.htm>.

DESAI, V. Community participation and slum housing. A study of Bombay. New Delhi: Sage, 1995.

DEWAN VERMA, G. Slumming India. A chronicle of slums and their saviours. Delhi: Penguin Books India, 2002.

DUPONT, V. Slum demolition in Delhi since the 1990. An appraisal. Economic and Political Weekly, Mumbai, v.43, n.28, p.79-87, 12 Jul. 2008.

DUPONT, V.; RAMANATHAN, U. Du traitement des slums à Delhi. Politiques de "nettoyage" et d'embellissement. In: DUPONT, V.; HEUZE, J. G. (Ed.) La ville en Asie du Sud: analyse et mise en perspective. Purushartha n.26. Paris: EHESS, 2007. p.91-131. 
GHERTNER, D. A. Analysis of new legal discourses behind Delhi's slum demolitions. Economic and Political Weekly, v.43, n.20, p.57-66. 17 May 2008.

GNCTD. Strategy paper on jhuggi jhompri clusters in Delhi. New Delhi: Government of National Capital Territory of Delhi, 1999.

GOI. National Housing Policy. New Delhi: Government of India, 1992.

Draft National Slum Policy. New Delhi: Government of India, Ministry of Urban Development and Poverty Alleviation, 1999.

INDIAN PEOPLE'S Tribunal on Environment and Human Rights. Bulldozing Rights - A Report on the Forced Evictions and Housing Policies for the Poor in Mumbai. Mumbai: Iptehr, Jun. 2005.

KUNDU, A. Provision of tenurial security for the urban poor in Delhi: recent trends and future perspectives. Habitat International, v.28, n.2, p.259-74, Jun. 2004.

OMCT/HIC-HLRN. Joint Urgent Action Appeal, Case IND-FE050504. Delhi, Geneva, Cairo: World Organisation against Torture, Habitat International Coalition-Housing and Land Rights Network, 5 May 2004.

PRIYA, R. Town planning, public health and urban poor, some explorations from Delhi. Economic and Political Weekly, Mumbai, v.28, n.17, p.824-34, 24 Apr. 1993.

RAMANATHAN, U. Demolition drive. Economic and Political Weekly, Mumbai, v.40, n.27, p.2908-12, 2 Jul. 2005.

. Illegality and the urban poor. Economic and Political Weekly, Mumbai, v.41, n.29, p.3193-7, 22 Jul. 2006.

RISBUD, N. The case of Mumbai, India. Understanding Slums: Case Studies for the Global Report on Human Settlements. UN-Habitat, 2003. Disponível em : <http://www.ihrn.gov. za/Current\%20Research/India/Mumbai_bw.pdf>.

SAGLIO-YATZIMIRSKY, M. C. Intouchable Bombay. Le bidonville des travailleurs du cuir. Paris: CNRS, 2002.

SANYAL, B., MUKHIJA V. Institutional pluralism and housing delivery: a case of unforeseen conflicts in Mumbai, India. World Development, v.29, n.12, p.2043-57, 2001.

WEINSTEIN, L. Mumbai's development mafias: globalization, organized crime and land development. International Journal of Urban and Regional Research, v.32, n.1, p.23-39, Mar. 2008.

ZÉRAH, M.-H. Conflict between green space preservation and housing needs: the case of the Sanjay Gandhi National Park in Mumbai. Cities, v.24, n.2, p.122-32, Apr. 2007.

RESUMO - Este artigo comparativo focaliza as políticas públicas adotadas para as favelas das duas maiores metrópoles indianas, Delhi, a capital política, e Mumbai, o principal centro econômico. Tentaremos entender as convergências e divergências existentes nas políticas das favelas aplicadas no período pós-independência, nas políticas de melhoria dos serviços básicos, de reassentamento e de urbanização. Como será mostrado, a explicação das principais diferenças tem como base as interações distintas de atores, públicos, privados e da sociedade civil, arraigadas em contextos urbanos específicos. 
PALAVRAS-CHAVE: Favelas, Políticas públicas, Urbanização, Reassentamento, Delhi, Mumbai.

ABSTRACT - This comparative article focuses on public policies regarding slums in the two largest Indian metropolises, Delhi, the political capital, and Mumbai, the foremost economic hub, which face different geomorphologic constraints. It highlights the similar trends and the divergences in slum polices implemented since the 1950's: environmental improvement, resettlement and in situ rehabilitation. The explanation of the main differences lies in distinctive interplays of actors: public, private and civil society.

KErWORDs: Slum, Public policies, Rehabilitation, Resettlement, Delhi, Mumbai.

Véronique Dupont é demógrafa, pesquisadora titular (senior fellow) na Universidade Paris 1 - IRD, UMR 201 "Desenvolvimento e Sociedade", pesquisadora associada no Centro de Estudos da Índia (Ceias, CNRS-Ehess, UMR 8564) e membro do programa Setup. @-veronique.dupont@ird.fr

Marie-Caroline Saglio-Yatzimirsky é antropóloga, professora doutora no Instituto National des Langues et Civilisation Orientales (Inalco, Paris, França), pesquisadora no Centro de Estudos da Índia (Ceias, CNRS-Ehess, UMP 8564) e coordenadora do Programa "Social Exclusion, Territories, Urban Policies in Índia and Brasil" (Setup, ANR, 2006-2009). @-marieyat@hotmail.com

Recebido em 18.5.2009 e aceito em 2.6.2009. 


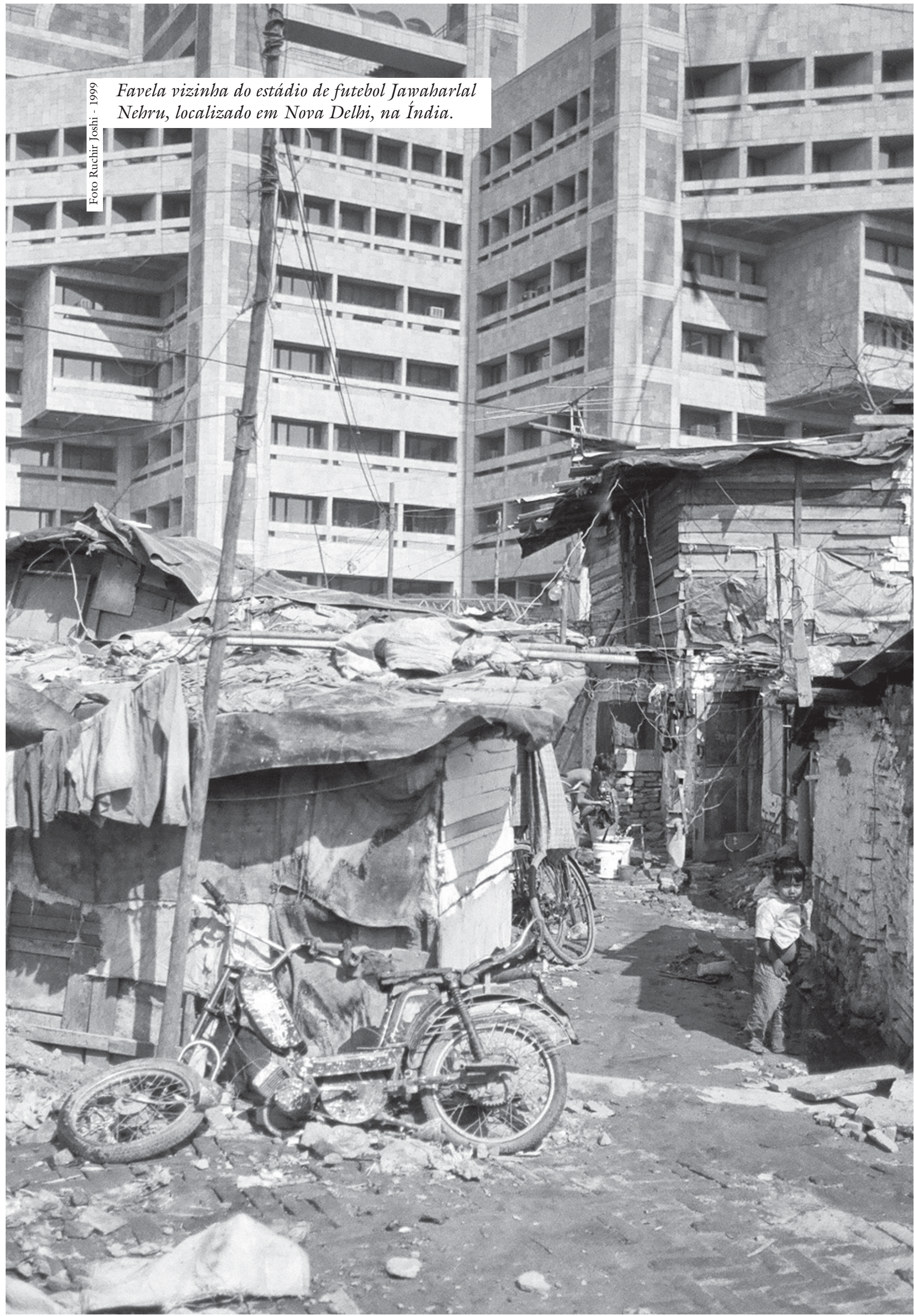

